\title{
Preferensi Publik terhadap Wakaf Uang di Sumatera Barat
}

\author{
Public Preference toward Cash Waqf in West Sumatera
}

\author{
Adila Adisti \\ Fakultas Ekonomi, Universitas Andalas, Limau Manis, Padang 25175, Indonesia, \\ adilaadisti@eb.unand.ac.id
}

\begin{abstract}
Cash waqf can be a solution in optimizing the potential of land waqf asset in Indonesia, in order to reach economic empowerment. In Indonesia, cash waqf had a great potential reaching 180 trillion rupiah, however the money acquired on 2019 only reached 400 billion rupiah. Several factors caused the low rate of accumulation of cash waqf, namely religiousity, cash waqf literacy, waqf inclusion, and waqf institution management. This study aims to find out public preference toward cash waqf specifically in West Sumatera Province. The analytical method used is PLS-SEM qualitative analysis using SmartPLS 3.9 .2 as a tool. Purposive sampling technique was used to assign 175 respondents. Results showed that there are positive and significant relationship between cash waqf literacy, waqf inclusion and waqf institution management variables with the public preference towards cash waqf. Whereas religiousity factor had positive but insignificant effect to the public preference of cash waqf.
\end{abstract}

Keywords: Cash waqf, cash waqf literacy, waqf inclusion, waqf institution management.

\begin{abstract}
Abstrak. Wakaf uang dapat menjadi salah satu solusi dalam mengoptimalkan potensi aset wakaf tanah yang dimiliki oleh Indonesia untuk dikelola sehingga dapat memberdayakaan ekonomi. Potensi wakaf uang di Indonesia sangatlah besar yaitu 180 triliun rupiah. Namun, hingga saat ini potensi yang sangat besar hanya dapat dihimpun sebesar 400 miliar rupiah pada tahun 2019. Rendahnya penghimpunan wakaf uang disebabkan oleh beberapa faktor, di antaranya religiusitas, literasi wakaf uang, inklusi wakaf, dan tata kelola lembaga wakaf. Penelitian ini bertujuan untuk mengetahui preferensi publik terhadap wakaf uang khususnya di Sumatera Barat. Metode analisis yang digunakan adalah analisis kuantitatif PLS-SEM dengan alat SmartPLS 3.9.2. Teknik purposive sampling digunakan untuk memilih sampel sebanyak 175 reponden di Sumatera Barat. Hasil dari penelitian ini menunjukan bahwa ada hubungan positif dan signifikan di antara variabel literasi wakaf uang, inklusi wakaf dan tata kelola wakaf dengan preferensi publik terhadap wakaf uang. Sedangkan variabel religiusitas berhubungan positif namun tidak signifikan terhadap preferensi wakaf uang.
\end{abstract}

Kata kunci: Inklusi wakaf, literasi wakaf uang, tata kelola wakaf, wakaf uang.

\section{PENDAHULUAN}

Wakaf sebagai salah satu filantropi Islam sudah dipraktikkan sejak kepemimpinan Rasulullah SAW. Wakaf yang pertama kali dilakukan oleh Rasulullah SAW yaitu wakaf tanah untuk dibangun masjid Quba di Madinah (Dompet Dhuafa, 2019). Di Indonesia, wakaf telah dipraktikkan sejak kedatangan Islam yang pada awalnya hanya untuk keperluan ibadah dengan mendirikan masjid dari tanah wakaf maupun untuk tanah pemakaman. Seiring berjalan waktu, wakaf di Indonesia berkembang mencakup kegiatan pendidikan seperti pendirian pondok pesantren dan madrasah, hingga meliputi pelayanan sosial seperti pendirian panti asuhan dan pelayanan kesehatan seperti klinik kesehatan bahkan rumah sakit (KNKS, 2019). Menurut data Kementerian Agama RI pada tahun 2020, aset tanah wakaf Indonesia adalah 52,230.43 ha yang tersebar di 390,086 lokasi seluruh Indonesia.

Wakaf di Indonesia lebih banyak dikelola secara manual di mana $72.62 \%$ pemanfaatannya masih untuk masjid dan musala (Kemenag RI, 2020). Aset wakaf yang potensial dan bernilai tinggi belum dikelola secara optimal untuk aktivitas produktif seperti pusat perdagangan, perhotelan, pabrik, rumah usaha, apartemen, dan pertanian. Optimalisasi aset wakaf dapat mendatangkan manfaat ekonomi khususnya untuk mauquf 'alaih dan masyarakat pada umumnya. Pengembangan aset wakaf 
memerlukan dana yang besar sehingga salah satu solusinya bisa melalui wakaf uang. Sejak dikeluarkannya UU No. 41 Tahun 2004, maka di Indonesia mulai dikenal bentuk lain dari wakaf yaitu wakaf tunai berupa uang. Wakaf uang (cash waqf) adalah wakaf dalam bentuk uang yang diberikan oleh individu, kelompok, lembaga maupun badan hukum (MUI, 2002). Sedangkan lembaga yang berwenang yang merupakan lembaga independen dalam mengelola dan mengembangkan wakaf di Indonesia adalah Badan Wakaf Indonesia (BWI).

Potensi wakaf uang di Indonesia sangatlah besar yaitu 180 triliun rupiah, dengan tingkat realisasi 400 miliar rupiah (KNKS, 2019). Namun dalam kenyataannya pengumpulan dana wakaf uang belum optimal. Hal ini disebabkan oleh beberapa faktor, di antaranya literasi, inklusi dan tata kelola wakaf uang (BKF Kemenkeu, 2019). Faktor mendasar yang membuat wakaf produktif lambat perkembangannya adalah karena lemahnya literasi wakaf produktif baik dari sisi wakif (pemberi wakaf), nazir (pengelola wakaf) (Hasim et al., 2016), maupun masyarakat secara umum. Indeks literasi wakaf (ILW) secara nasional masuk dalam kategori rendah dengan skor sebesar 50.48 (BWI, 2020). Literasi wakaf merupakan faktor penentu yang memengaruhi tingkat partisipasi wakaf (Adeyemi et al., 2016; Shukor et al., 2017; Hasim et al., 2016; Osman et al., 2012). Literasi meliputi pemahaman model wakaf uang, tingkat pendidikan, sosialisasi, dan program atau kegiatan wakaf uang.

Jika dilihat dari segi inklusi wakaf, kenyamanan mengakses lembaga wakaf menurut Shukor et al. (2017) berkontribusi dalam partisipasi wakaf uang, penggunaan metode pembayaran wakaf yang mudah (Faradis, 2015) serta adopsi teknologi pada wakaf uang. Selain itu, level pendapatan (BKF Kemenkeu, 2019) dan tingkat pendidikan (Dahlan, 2017) juga dapat memengaruhi preferensi wakaf uang di Indonesia. Dari sisi tata kelola wakaf uang, yang menjadi penyebab rendahnya partisipasi masyarakat adalah masalah nazir (Huda et al., 2014) yaitu berkaitan dengan profesionalitas lembaga dan manajemen yang efisien (Yusof et al., 2013; Hasim et al., 2016).

Faktor lain adalah kemudahan untuk komplain kepada BWI maupun kepada lembaga berwenang lainnya (Faradis, 2015). Promosi yang dilakukan lembaga wakaf juga dianggap sangat penting memengaruhi penghimpunan dana wakaf uang. Namun di sisi lain, hal penting yang menjadi pendorong orang untuk berpatisipasi dalam wakaf uang adalah tingkat religiusitas. Dukungan pemerintah sangat diperlukan baik dari segi anggaran maupun fasilitas layanan administrasi wakaf serta sebaran lembaga wakaf di daerah sesuai dengan potensi yang ada di setiap daaerah tersebut (Nizar, 2014).

Sumatera Barat berpenduduk 5,441,197 jiwa di mana 98\% di antaranya adalah beragama Islam (Kemenag Sumbar, 2019). Potensi wakaf uang di Sumatera Barat adalah sebesar 2 sampai 5 miliar rupiah dalam setahun (Kemenag Sumbar, 2019). Beberapa lembaga nazir wakaf uang yang terdaftar di BWI Sumatera Barat yaitu Koperasi Jasa Keuangan Syariah (KJKS) Alang Laweh, KJKS Seberang Padang, Koperasi Simpan Pinjam Syariah (KSPPS) BMT Alfataya dan Badan Pengelola Wakaf (BPW) Ar Risalah Padang. Berdasarkan hasil interview dengan lima lembaga nazir tersebut belum ada yang mengelola wakaf uang secara produktif karena kurangnya pengetahuan masyarakat Sumatera Barat, terlihat dari rendahnya indeks literasi wakaf Sumatera Barat dengan skor 54,95 (BWI, 2020) serta kurangnya kontribusi masyarakat Sumatera Barat terhadap wakaf uang. Berdasarkan hal tersebut, maka dalam penelitian ini membahas hubungan antara religiusitas, literasi, inklusi wakaf, dan tata kelola wakaf terhadap preferensi wakaf uang di Sumatera Barat.

\section{TINJAUAN PUSTAKA}

\section{Wakaf}

Wakaf berasal dari bahasa Arab yaitu waqafa (sinonim habasa) yang bermakna berhenti, menahan atau diam. Mahzab Syafi'iyah mendefinisikan wakaf sebagai penyerahan harta yang bermanfaat serta kekal materi bendanya (al-'ain) kepada nazir sesuai ketentuan syariah. Jika harta yang diwakafkan 
telah diserahkan kepada nazir, maka terputuslah hak pengelolaan wakif terhadap harta tersebut (DEKS BI dan DES FEB UNAIR, 2016). Apabila kata wakaf dihubungkan dengan kata harta, dimaknai sebagai pembekuan hak milik untuk manfaat tertentu (BKF Kemenkeu, 2019).

Az-Zuhaili (2011) menjelaskan wakaf yang sah harus memenuhi rukun dan syarat. Ada empat rukun wakaf yaitu al-waqif (pihak yang berwakaf), al-mauquf (objek wakaf berupa harta, aset atau barang), mauquf 'alaih (penerima wakaf) dan sighat (ikrar wakaf). Berdasarkan jenis harta, wakaf dibagi menjadi tiga aspek. Pertama, wakaf benda tidak bergerak misalnya tanah, bangunan, tanaman beserta tanah. Kedua, wakaf benda bergerak seperti bahan bakar, surat berharga, hak kekayan intelektual (HKI). Ketiga, benda bergerak dalam bentuk uang (wakaf uang, cash waqf) (DEKS BI dan DES FEB UNAIR, 2016).

Menurut Fatwa Majelis Ulama Indonesia (MUI) tahun 2002, wakaf uang adalah wakaf dalam bentuk uang yang diberikan oleh individu, kelompok, lembaga, maupun badan hukum yang diserahkan ke pengelola. Wakaf uang bisa dikelompokan menjadi wakaf uang secara langsung (direct cash waqf) maupun tidak langsung (indirect cash waqf). Wakaf uang secara langsung dapat diberikan oleh wakif kepada mauquf 'alaih sehingga dapat dikelola langsung dalam bentuk waqf property seperti rumah sakit, sekolah, hotel, apartemen. Sedangkan konsep inderect cash waqf dikumpulkan dari wakif dan mauquf alaih menginvestasikan kepada jenis usaha yang sesuai dengan syariah sehingga menghasilkan profit bagi hasil. Jenis wakaf ini dapat dijadikan sebagai alternatif pembiayaan bagi lembaga pendidikan dan kesehatan Islam juga sangat potensial membantu pelaku Usaha Menengah Kecil Mikro (UMKM) (Syafiq, 2014). Praktik wakaf uang di Indonesia telah dilakukan oleh Tabung Wakaf Indonesia (TWI) yang mengelola sektor pendidikan seperti SMART Ekselensia, Rumah Cahaya, sektor kesehatan, sektor dakwah, dan mencakup Wisma Mualaf dan sektor ekonomi.

\section{Preferensi}

Preferensi merupakan salah satu konsep dasar yang digunakan dalam ilmu ekonomi dalam menjelaskan perilaku individu dalam menentukan pilihan seperti bagaimana mengidentifikasi dan mengukur preferensi individual terhadap set alternatif dan bagaimana membangun preferensi yang menggambarkan fungsi untuk melakukan pilihan. Preferensi dapat dipengaruhi oleh kepribadian, psikologi, sosial, dan kebudayaan (Setiadi, 2013). Selain itu identitas agama berpengaruh kepada individuals' economic outcomes (Benjamin et al., 2016). Agama juga berkorelasi dengan banyak faktor dalam ekonomi dan pada akhir memengaruhi perilaku seseorang (Benjamin et al., 2016). Dalam Islam, preferensi dalam menentukan pilihan-pilihan harus mengandung maslahah (manfaat).

\section{Religiusitas}

Wakaf terdiri dari dua dimensi yaitu religuisitas dan sosial ekonomi. Dimensi religiusitas artinya bahwa wakaf adalah tanggung jawab setiap Muslim dengan imbalan pahala yang terus mengalir meskipun si pemberi wakaf telah wafat. Sedangkan dimensi sosial ekonomi adalah dapat membantu masyarakat dalam penyediaan fasilitas publik, mendorong pemberdayaan ekonomi dengan produktivitas aset wakaf (Affandi \& Nufus, 2010). Religiusitas diartikan sebagai kepercayaan pada Tuhan diiringi dengan komitmen untuk menjalankan prinsip yang diyakini (McDaniel \& Burnett, 1990). Level di mana individu komit dengan kepercayaan agama akan memengaruhi sikap dan perilaku seseorang (Alhidari, 2013).

Dalam penelitian ini religiusitas merujuk pada konsep yang dikemukakan oleh Alsanie (1989) (Alhidari, 2013) di mana terdapat dua dimensi religiusitas yaitu dimensi keyakinan dan praktik (belief and action). Dimensi keyakinan yang digunakan terdiri dari keyakinan kepada Allah dan menjadikan agama Islam sebagai panduan hidup. Selain itu, religusitas artinya mengikuti segala perintah-Nya dengan sungguh-sungguh dan menjalankan kewajiban sebagai Muslim (seperti salat lima waktu, puasa dan zakat). Sedangkan dimensi praktik adalah berbuat baik kepada sesama untuk mendapat rida dan pahala dari Allah. 
Berbagai penelitian yang dilakukan menjelaskan pengaruh religiusitas tehadap perilaku individual Muslim dalam beramal (charitable behavior). Motivasi terkuat seseorang untuk beramal adalah agama (Kasri, 2013 dan Opoku, 2013) dan dapat memengaruhi frekuensi berdonasi (de Abreu, 2015). Ditemukan pengaruh positif antara individual dengan religiusitas menonjol (melaksanakan salat, zakat dan puasa) dengan jumlah donasi dan efek terhadap distribusi memberi (Lambarraa dan Riener, 2015). Religiusitas tidak selalu memengaruhi seseorang melakukan donasi, ia hanya sebagai faktor moderat yang memengaruhi sikap bedonasi. Hasil penelitian di Saudi Arabia menunjukkan religiusitas tidak berpengaruh sama sekali terhadap perilaku donasi (Alhidari, 2013).

Studi lain menunjukan bahwa religusitas merupakan faktor utama yang memengaruhi seseorang untuk berwakaf uang (Mokthar, 2016), bahkan dapat membuat seseorang berkontribusi kembali dalam melakukan wakaf uang (Johari et al., 2015). Religiusitas juga memengaruhi perilaku Muslim untuk berpartisipasi dalam wakaf uang (Shukor et al., 2017). Faktor penentu preferensi masyarakat Muslim terhadap wakaf uang adalah religiusitas (Faradis, 2015). Di sisi lain, studi yang dilakukan oleh Osman et al. (2014) menemukan bahwa religiusitas memengaruhi keinginan dalam berwakaf di antara intelektual muda di Malaysia meskipun hanya pada tingkat signifikan $10 \%$.

\section{Literasi}

Pengetahuan adalah penyajian oleh jiwa yang rasional dan tenang (al-nafs al-na, tiqah almutma'innah), tentang makna sebenarnya dari benda-benda, bentuk lahiriahnya, ketika melepaskan materi di dalam dirinya, cara mereka, kuantitasnya, substansinya, dan esensi mereka (Al-Ghazali, 1995). Berdasarkan pengetahuan manusia bebas memilih berinteraksi dengan berbagai alternatif (Mokthar, 2016). Pengetahuan merupakan faktor yang sangat mentukan tingkat literasi seseorang, orang yang memiliki pengetahuan mengenai sesuatu hal dapat dikatakan memiliki tingkat literasi yang lebih baik. Secara etimologi literasi berasal dari istilah latin literature dan bahasa Inggris letter. Literasi keuangan adalah keyakinan, pengetahuan disertai keterampilan keuangan yang dapat memengaruhi perilaku seseorang untuk mengambil keputusan dalam pengelolaan keuangan untuk mencapai kesejahteraan (OJK, 2016).

Pengetahuan seseorang tentang charities merupakan faktor yang menentukan bagaimana pandangannya terhadap beramal (Bennett dan Savani, 2003). Hasil penelitian menjelaskan bahwa kurangnya kesadaran tentang wakaf disebabkan oleh rendahnya pemahaman wakaf terutama land waqf (Puad et al., 2014), hal yang sama terjadi pada wakaf uang (Adeyemi et al., 2016). Rendahnya pengetahuan tentang wakaf uang disebabkan asumsi bahwa wakaf hanya terbatas pada aset tetap seperti lahan, bangunan, serta kuburan (Yusof et al., 2013; Siswantoro \& Dewi, 2011) Keinginan untuk melakukan wakaf uang berhubungan dengan pengetahuan wakaf uang (Mokthar, 2016), dan Shukor et al. (2017) menyimpulkan bahwa pengetahuan tentang wakaf uang tidak berpengaruh pada sikap seseorang untuk berwakaf uang.

Secara nasional Indeks Literasi Wakaf (ILW) Indonesia masuk dalam kategori rendah dengan skor sebesar 50.48 (BWI, 2020). Penelitian yang dilakukan Badan Kebijakan Fiskal Indonesia tahun 2019 yang mengukur indeks literasi wakaf uang menafsirkan literasi wakaf adalah pengetahuan umum yang dimiliki oleh individu tentang wakaf. Seberapa paham masyarakat tentang makna wakaf, familiar istilah dan badan wakaf berwenang. Indeks literasi wakaf uang di Indonesia ditentukan menggunakan simple weighted index dan menyimpulkan bahwa tingkat literasi cenderung rendah atau masuk kategori kurang baik. Sedangkan literasi wakaf uang merupakan faktor potensial dalam mendorong individu untuk berpartisipasi dalam wakaf uang (Osman et al., 2012).

\section{Inklusi Wakaf Uang}

Inklusi keuangan adalah akses yang tersedia pada lembaga, produk dan layanan jasa keuangan (baik konvensional maupun syariah) sesuai dengan kebutuhan dan kemampuan masyarakat untuk meningkatkan kesejahteraan mereka (OJK, 2016). Istilah inklusi belum banyak digunakan dalam kajian tentang wakaf. Istilah ini diadopsi dari Badan Kebijakan Fiskal Indonesia 2019 yang meneliti 
bahwa ada beberapa faktor yang termasuk dalam inklusi wakaf. Faktor tersebut yaitu kepercayaan pada institusi yang dapat meningkatkan kontribusi wakaf uang, kenyamanan dalam berwakaf yang cenderung meningkatkan intensitas orang untuk berwakaf uang, penggunaan teknologi dalam wakaf uang, serta level pendapatan yang berpengaruh pada preferensi melakukan wakaf uang.

Beberapa penelitian yang dapat dikategorikan pada pengaruh inklusi wakaf uang terhadap preferensi wakaf uang adalah faktor kepercayaan terhadap nazir, kenyamanan mengakses lembaga wakaf (Shukor et al., 2017 dan Yusof et al., 2013). Faktor lain yang memengaruhi penghimpunan wakaf adalah tingkat pendidikan (Dahlan, 2017), penggunaa metode pembayaran wakaf yang mudah (Faradis, 2015) serta adopsi teknologi pada wakaf uang dan level pendapatan berperan dalam preferensi wakaf uang di Indonesia (BKF Kemenkeu, 2019).

\section{Tata Kelola Wakaf Uang}

Tata kelola wakaf uang adalah bagaimana masyarakat menilai lembaga berwenang mengelola dengan baik sehingga muncul kepercayaan yang memengaruhi preferensi sesorang dalam melakukan wakaf uang. Huda et al. (2014) menyatakan bahwa yang paling bermasalah dalam penghimpunan wakaf uang di Indonesia adalah nazir. Faktor yang memengaruhi persepsi masyarakat dalam berwakaf adalah profesionalitas lembaga dan manajemen yang efisien (Johari et al., 2015 dan Hasim et al., 2016). Selain itu, faktor lainnya yaitu pemahaman nazir tentang model wakaf (Hasim et al., 2016), termasuk kemudahan untuk komplain kepada BWI maupun kepada lembaga berwenang lainnya (Faradis, 2015). Rendahnya kesadaran tentang wakaf tunai di Malaysia adalah karena kurang promosi oleh lembaga wakaf (Adeyemi et al., 2016).

\section{Definisi Operasional Variabel}

Tabel 1 Definisi operasional variabel

\begin{tabular}{|c|c|c|}
\hline Variabel & Definisi Variabel & Referensi \\
\hline $\begin{array}{l}\text { Preferensi } \\
\text { Wakaf Uang } \\
\text { (Y) }\end{array}$ & $\begin{array}{l}\text { Preferensi adalah perilaku individu dalam menentukan } \\
\text { pilihan yang dapat dipengaruhi oleh kepribadian, } \\
\text { psikologi, sosial dan kebudayaan dan identitas agama. }\end{array}$ & $\begin{array}{l}\text { Setiadi (2013) } \\
\text { Benjamin et al. (2016) }\end{array}$ \\
\hline $\begin{array}{l}\text { Religiusitas } \\
\left(\mathrm{X}_{1} ; \mathrm{Rel}\right)\end{array}$ & $\begin{array}{l}\text { Religiusitas adalah keyakinan kepada Allah dan } \\
\text { menjadikan agama Islam sebagai panduan hidup. } \\
\text { Religusitas artinya mengikuti segala perintah-Nya dengan } \\
\text { sungguh-sungguh, menjalankan kewajiban sebagai } \\
\text { Muslim (seperti salat lima waktu, puasa dan zakat), dan } \\
\text { berbuat baik kepada sesama untuk mendapat rida dan } \\
\text { pahala dari Allah. }\end{array}$ & $\begin{array}{l}\text { Alsanie (1989) } \\
\text { Osman et al. (2014) }\end{array}$ \\
\hline $\begin{array}{l}\text { Literasi Wakaf } \\
\text { Uang }\left(\mathrm{X}_{2} ; \text { Lit }\right)\end{array}$ & $\begin{array}{l}\text { Literasi wakaf uang dimaknai sebagai pengetahuan dasar } \\
\text { tentang wakaf uang, dasar hukum wakaf uang, perbedaan } \\
\text { wakaf dan zakat, lembaga pengelola wakaf uang dan } \\
\text { program pengelolaan wakaf uang. }\end{array}$ & $\begin{array}{l}\text { Osman et al. }(2012) \\
\text { Nizar (2014) } \\
\text { Adeyemi et al. }(2016) \\
\text { Dahlan (2017) }\end{array}$ \\
\hline $\begin{array}{l}\text { Inklusi Wakaf } \\
\text { Uang }\left(\mathrm{X}_{3} ; \text { Ink }\right)\end{array}$ & $\begin{array}{l}\text { Inklusi wakaf uang adalah kepercayaan pada institusi } \\
\text { wakaf uang dan nazir, kenyamanan dalam berwakaf dan } \\
\text { mengakses lembaga wakaf, metode pembayaran wakaf } \\
\text { yang mudah serta penggunaan teknologi dalam wakaf } \\
\text { uang. }\end{array}$ & $\begin{array}{l}\text { Yusof et al. (2013) } \\
\text { Faradis (2015) } \\
\text { Shukor et al. ( 2017) } \\
\text { BKF Kemenkeu (2019) }\end{array}$ \\
\hline $\begin{array}{l}\text { Tata Kelola } \\
\text { Wakaf Uang } \\
\left(\mathrm{X}_{4} ; \text { Takel }\right)\end{array}$ & $\begin{array}{l}\text { Tata kelola wakaf uang adalah berkaitan dengan lembaga } \\
\text { wakaf uang itu sendiri. Di antaranya profesionalitas } \\
\text { lembaga dan manajemen yang efisien. Kemudahan } \\
\text { mengetahui program wakaf uang, penyalurannya serta } \\
\text { laporan penggelolaan wakaf uang. Serta inovasi yang } \\
\text { dilakukan lembaga wakaf dalam mengumpulkan wakaf } \\
\text { uang. }\end{array}$ & $\begin{array}{l}\text { Johari et al. (2015) } \\
\text { Hasim et al. (2016) }\end{array}$ \\
\hline
\end{tabular}




\section{Hipotesis}

H1: Religiusitas berpengaruh positif dan signifikan terhadap preferensi wakaf uang

$\mathrm{H} 2$ : Literasi wakaf uang berpengaruh positif dan signifikan terhadap preferensi wakaf uang

H3: Inklusi wakaf uang berpengaruh positif dan signifikan terhadap preferensi wakaf uang

H4: Tata kelola wakaf berpengaruh positif dan signifikan terhadap preferensi wakaf uang

Berikut kerangka teori preferensi publik terhadap wakaf uang:

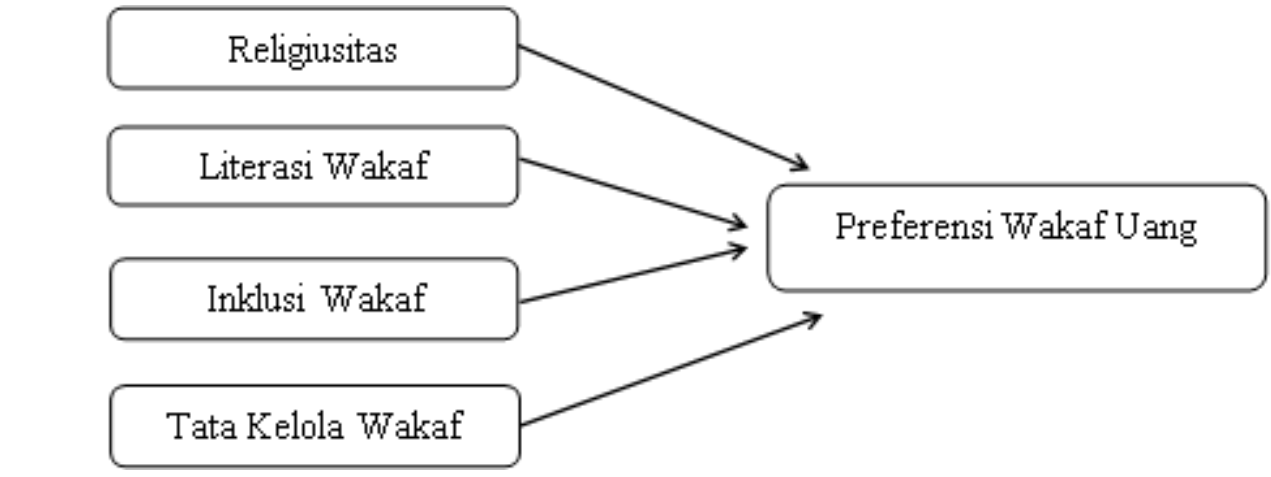

Sumber: Ilustrasi Penulis, 2020

Gambar 1 Model faktor memengaruhi preferensi wakaf uang

\section{METODE}

Metode analisis yang digunakan dalam penelitian adalah analisis kuantitatif PLS-SEM dengan alat SmartPLS 3.9.2. Pengambilan sampel menggunakan teknik purposive sampling, dengan memilih sampel reponden berdasarkan pertimbangan karakteristik yang cocok untuk menjawab tujuan penelitian (Juanda, 2009). Menurut Hair et al. (2013), agar tingkat statistical power sampel cukup, maka penentuan besar sampel sebaiknya merujuk kepada rumus Cohen (1992). Untuk statistical power $80 \%$ dengan significant level $5 \%$ dan empat variabel independent, maka jumlah minimum sampel adalah 65 (Hair et al., 2013). Survei responden dilakukan dengan kuisioner daring. Dari 197 kusioner yang direspons, terdapat 22 responden yang tidak sesuai kriteria. Sehingga ada 175 yang memenuhi kriteria untuk dilakukan pengolahan data.

\section{HASIL DAN PEMBAHASAN}

\section{Profil Responden}

Berdasarkan Tabel 2, dapat dilihat bahwa jumlah responden terbanyak adalah perempuan yakni sebesar 51\%. Sisanya responden berjenis kelamin laki-laki sebanyak 49\%. Menurut kelompok umur, responden terbanyak adalah responden berumur $18-34$ tahun yaitu 52\%. Selanjutnya responden dengan umur $35-51$ adalah $30 \%$ dan responden dengan umur $52-67$ tahun dengan jumlah responden $18 \%$. Jumlah responden dengan status pernikahan menikah lebih banyak yakni sebanyak $65 \%$. Di sisi lain responden yang paling sedikit yaitu responden dengan status pernikahan cerai mati dan cerai hidup yakni 3\% dan responden dengan status pernikahan belum menikah memiliki persentase 29\%. Jika dilihat dari latar belakang pendidikan, jumlah responden yang berpendidikan Diploma/Sarjana (S1) lebih banyak yakni sebanyak 74 orang. Sedangkan responden yang paling sedikit adalah responden dengan latar belakang pendidikan Doktor (S3) yakni sebanyak 14 responden. Responden dengan pendidikan Master (S2) memiliki jumlah 46 orang responden dan responden dengan pendidikan Sekolah Menengah Atas (SMA) memiliki jumlah responden sebanyak 41. 
Tabel 2 Profil demografi responden

\begin{tabular}{|c|c|c|}
\hline Karakteristik & Jumlah (orang) & $\begin{array}{c}\text { Persentase } \\
(\%)\end{array}$ \\
\hline \multicolumn{3}{|l|}{ Jenis Kelamin } \\
\hline Laki-laki & 86 & $49 \%$ \\
\hline Perempuan & 89 & $51 \%$ \\
\hline \multicolumn{3}{|l|}{ Rentang Usia pada Tahun 2020} \\
\hline $18-34$ Tahun & 92 & $52 \%$ \\
\hline $35-51$ Tahun & 52 & $30 \%$ \\
\hline $52-67$ Tahun & 31 & $18 \%$ \\
\hline$>68$ Tahun & 0 & $0 \%$ \\
\hline \multicolumn{3}{|l|}{ Status Pernikahan } \\
\hline Belum Menikah & 51 & $29 \%$ \\
\hline Menikah & 114 & $65 \%$ \\
\hline Cerai Hidup & 5 & $3 \%$ \\
\hline Cerai Mati & 5 & $3 \%$ \\
\hline \multicolumn{3}{|l|}{ Pendidikan Terakhir } \\
\hline Sekolah Menengah Atas (SMA) & 41 & $24 \%$ \\
\hline Diploma/Sarjana (S1) & 74 & $42 \%$ \\
\hline Master (S2) & 46 & $26 \%$ \\
\hline Doktor (S3) & 14 & $8 \%$ \\
\hline \multicolumn{3}{|l|}{ Pekerjaan Saat ini } \\
\hline Pegawai Negeri Sipil & 63 & $36 \%$ \\
\hline Pegawai Swasta & 22 & $12 \%$ \\
\hline Wirausaha & 22 & $12 \%$ \\
\hline Lainnya & 68 & $40 \%$ \\
\hline \multicolumn{3}{|l|}{ Pendapatan Rata-rata per Bulan } \\
\hline$<\operatorname{Rp} 5,000,000$ & 98 & $56 \%$ \\
\hline $\operatorname{Rp} 5,000,001-\operatorname{Rp} 10,000,000$ & 59 & $33 \%$ \\
\hline $\operatorname{Rp} 10,000,001-\operatorname{Rp} 15,000,000$ & 10 & $6 \%$ \\
\hline $\operatorname{Rp} 15,000,001-\operatorname{Rp} 20,000,000$ & 5 & $3 \%$ \\
\hline Lebih dari Rp 20,000,001 & 3 & $2 \%$ \\
\hline \multicolumn{3}{|l|}{ Partisipasi Wakaf Uang } \\
\hline Tidak Pernah & 30 & $17 \%$ \\
\hline Jarang & 60 & $34 \%$ \\
\hline Kadang-Kadang & 50 & $29 \%$ \\
\hline Sering & 30 & $17 \%$ \\
\hline Sangat Sering & 5 & $3 \%$ \\
\hline
\end{tabular}

Sumber: Data primer, 2020 (diolah)

Karakteristik responden berdasarkan pekerjaan saat ini, pekerjaan tersebut di antaranya pegawai BUMN, karyawan honorer, non-PNS, pensiunan PNS, petani, ibu rumah tangga, mahasiswa, dll., dengan banyak responden 68 orang dengan persentase $40 \%$. Partisipasi yang paling sedikit adalah responden dengan pekerjaan wirausaha dan pegawai swasta dengan jumlah responden masing-masing sebanyak 22 responden dengan persentase $12 \%$. Sedangkan responden dengan pekerjaan Pegawai Negeri Sipil sebanyak 63 responden dengan persentase $36 \%$. 
Jika dikelompokkan berdasarkan pendapatan rata-rata per bulan, jumlah responden terbanyak adalah responden dengan rata-rata pendapatan perbulannya < Rp 5,000,000 yakni sebanyak 98 orang (56\%). Partisipasi yang paling sedikit adalah responden yang pendapatan lebih dari Rp 20,000,001 yakni 3 (2\%). Sedangkan responden dengan pendapatan $\mathrm{Rp} 5,000,001$ - Rp 10,000,000 memiliki jumlah responden 59 orang (33\%). Responden dengan pendapatan Rp 10,000,001 - Rp 15,000,000 memiliki 10 orang responden $(6 \%)$ dan responden dengan pedapatan $\mathrm{Rp} \mathrm{15,000,001} \mathrm{-} \mathrm{Rp} \mathrm{20,000,000} \mathrm{memiliki}$ 5 orang responden $(3 \%)$.

Jika dilihat berdasarkan tingkat partisipasi wakaf uang yang dilakukan responden dalam enam bulan terakhir menunjukan bahwa $34 \%$ responden jarang melakukan wakaf uang, sedangkan hanya 3\% responden sangat sering berpartisipasi wakaf uang. Sebanyak $17 \%$ responden tidak pernah sama sekali berpartisipasi dalam wakaf uang, sebanding dengan responden yang mengatakan sering melakukan wakaf uang. Sisanya yaitu sebesar $29 \%$ reponden mengakui bahwa kadang-kadang ikut partisipasi wakaf uang. Jika dilihat dari besaran wakaf uang yang pernah dilakukan oleh responden dalam satu tahun terakhir yaitu mulai dari Rp 25,000 sampai Rp 5000,000.

\section{Model Pengukuran (Outer Model)}

Model pengukuran adalah pengukuran reflektif dengan menguji validitas variabel dan reliabilitas instrumen.

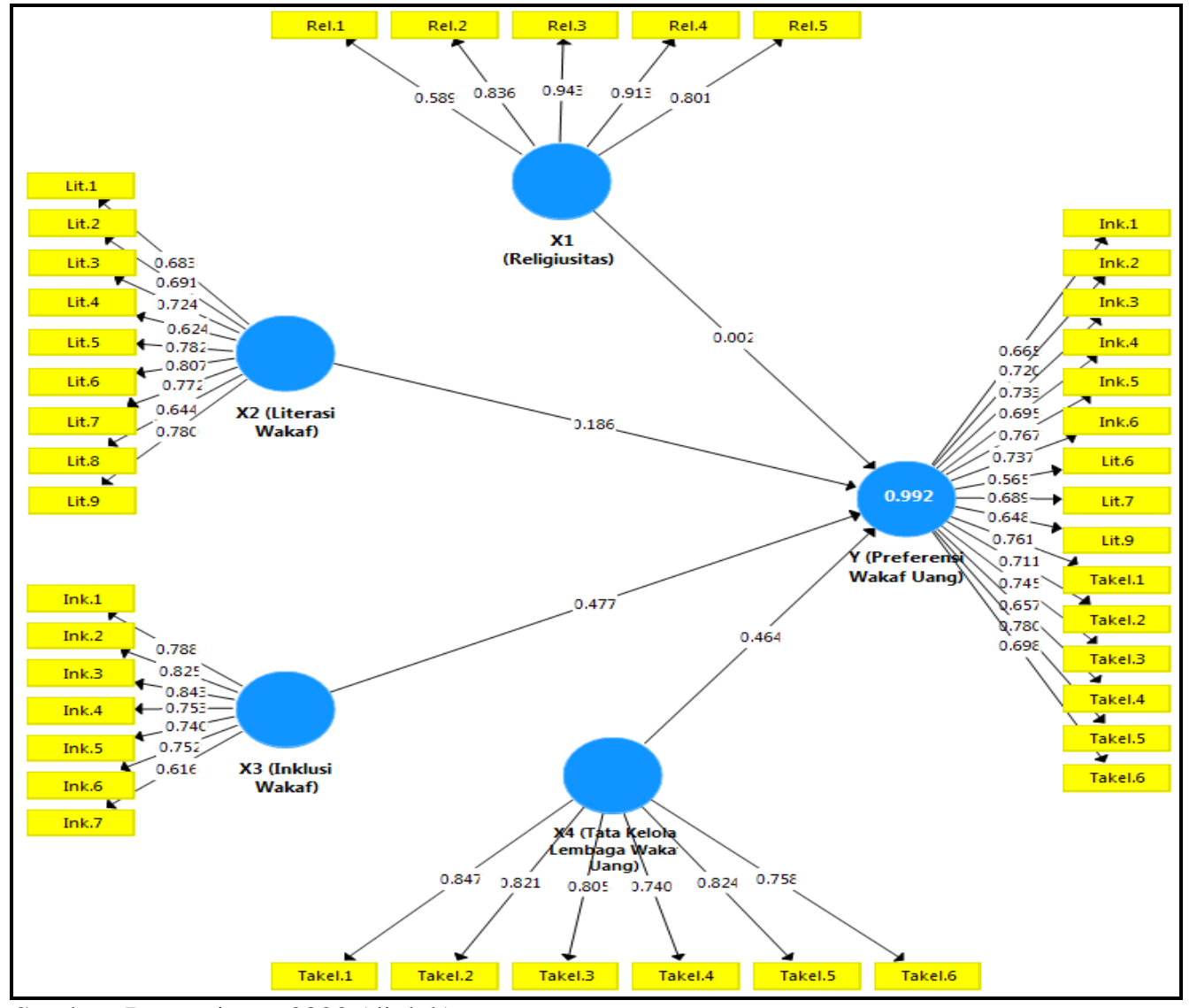

Sumber: Data primer, 2020 (diolah)

\section{Gambar 2 Outer model}

Gambar 2 merupakan model pengukuran berdasarkan uji convergen validity dari indikator-indikator yang mengukur konstruk (Abdillah dan Hartono, 2015). Gambar di atas merupakan indikator yang memiliki outer loading $>0.5$, indikator yang tidak memiliki nilai outer loading kurang dari 0.5 harus dihapus. Indikator-indikator yang telah didrop agar dapat memenuhi syarat 0.5 adalah indikator pada variabel Y (preferensi wakaf uang) yaitu Rel.1, Rel.2, Rel.3, Rel.4 Rel.5, Lit.1 Lit.2 Lit.3 Lit.4, Lit.5 
Lit.8, Lit.10, Ink.7 dan indikator pada variabel $\mathrm{X}_{2}$ (literasi wakaf) yaitu Lit.10. Nilai yang tidak memenuhi syarat tersebut dihapus karena dianggap tidak valid dan indikator dianggap tidak mampu untuk mengukur variabel. Kalkulasi ulang dilakukan dengan pengedropan kembali hingga nilai AVE sama atau lebih besar dari 0.5. Setelah melakukan pengujian sebanyak tiga kali, maka diperoleh nilai AVE lebih besar dari 0.5 seperti yang disajikan pada Tabel 3 berikut:

Tabel 3 Hasil Average Variance Extracted (AVE), cronbach's alpha dan composite reliability

\begin{tabular}{lccc}
\hline \multicolumn{1}{c}{ Variabel } & $\begin{array}{c}\text { Average Variance } \\
\text { Extracted (AVE) }\end{array}$ & $\begin{array}{c}\text { Cronbach's } \\
\text { Alpha }\end{array}$ & $\begin{array}{c}\text { Composite } \\
\text { Realibility }\end{array}$ \\
\hline X $_{1}$ (Religiusitas) & 0.682 & 0.926 & 0.913 \\
X $_{2}$ (Literasi Wakaf) & 0.527 & 0.888 & 0.909 \\
X $_{3}$ (Inklusi Wakaf) & 0.582 & 0.878 & 0.906 \\
X $_{4}$ (Tata Kelola Lembaga Wakaf & 0.640 & 0.887 & 0.914 \\
Uang) & 0.500 & 0.928 & 0.937 \\
Y (Preferensi Wakaf Uang) & & &
\end{tabular}

Sumber: Data primer, 2020 (diolah)

Uji reliabilitas dapat dilakukan degan menggunakan dua metode, yaitu cronbach's alpha dan composite reliability. Cronbach's alpha digunakan untuk mengukur batas bawah nilai reliabilitas suatu konstruk, sedangkan untuk mengukur nilai yang sebenarnya reliabilitas suatu konstruk menggunakan composite reliability (Abdillah dan Hartono, 2015). Suatu variabel atau konstruk dikatakan reliabel apabila nilai dari cronbach's alpha lebih besar dari 0.6 dan composite reliability lebih besar dari 0.7. Tabel 3 adalah hasil output cronbach's alpha dan composite reliability yang dilakukan dalam penelitian ini dengan mengggunakan program SmartPLS v.3.2.9. Berdasarkan Tabel 3 terlihat bahwa nilai cronbach's alpha konstruk reflektif yang diukur mempunyai nilai lebih besar dari 0.6 dan nilai composite realibility di atas 0.7 sehingga konstruk dalam penelitian ini dikatakan reliabel.

\section{Discriminant Validity}

Discriminant validity dapat dinilai berdasarkan Fornell-Larcker Criterion, jika korelasi konstruk yang memiliki item pengukuran bernilai lebih besar dari 0.7, artinya konstruk laten dapat memprediksi ukuran pada blok mereka dengan baik dan dikatakan bahwa konstruk memiliki discriminant validity. Berikut hasil discriminant validity masing-masing konstruk laten dapat dilihat dari Tabel 4. Tabel 4 adalah hasil Fornell-Larcker criterion dengan nilai korelasi konstruk yaitu > 0.7. Dapat disimpulkan bahwa konstruk laten menunjukkan discriminant validity yang baik, sehingga dapat dikatakan bahwa data tersebut valid.

Tabel 4 Hasil Fornell-Larcker criterion

\begin{tabular}{|c|c|c|c|c|c|}
\hline & $\begin{array}{c}\mathrm{X1} \\
\text { (Religiusitas) }\end{array}$ & $\begin{array}{c}\text { X2 } \\
\text { (Literasi } \\
\text { Wakaf) }\end{array}$ & $\begin{array}{c}\text { X3 } \\
\text { (Inklusi } \\
\text { Wakaf) }\end{array}$ & $\begin{array}{c}\text { X4 (Tata } \\
\text { Kelola } \\
\text { Lembaga } \\
\text { Wakaf } \\
\text { Uang) } \\
\end{array}$ & $\begin{array}{c}\text { Y (Preferensi } \\
\text { Wakaf Uang } \\
\text { Indonesia) }\end{array}$ \\
\hline $\mathrm{X} 1$ (Religiusitas) & 0.826 & & & & \\
\hline X2 (Literasi Wakaf) & 0.179 & 0.726 & & & \\
\hline $\begin{array}{l}\text { X3 (Inklusi Wakaf) } \\
\text { X4 (Tata Kelola }\end{array}$ & 0.072 & 0.576 & 0.763 & & \\
\hline $\begin{array}{l}\text { Lembaga Wakaf Uang) } \\
\text { Y (Preferensi Wakaf }\end{array}$ & 0.037 & 0.531 & 0.725 & 0.800 & \\
\hline Uang Indonesia) & 0.086 & 0.707 & 0.92 & 0.908 & $\mathbf{0 . 7 0 7}$ \\
\hline
\end{tabular}




\section{Model Struktural (Inner Model)}

Model struktural (inner model) digunakan untuk mengetahui hubungan kausalitas di antara variabel laten. Penelitian ini menggunakan coefficient of determination $\left(\mathrm{R}^{2}\right)$ untuk uji model dan path coefficient ( $\beta$ ) untuk uji hipotesisnya. Pengukuran dalam model struktural dilakukan dengan mengetahui nilai R-square. Dengan mengetahui nilai R-square maka dapat terlihat pengaruh variabel independen terhadap variabel dependen.

\begin{tabular}{cc}
\multicolumn{2}{c}{ Tabel 5 R-Square } \\
\hline Variabel & R- Square \\
\hline Y (preferensi wakaf uang) & 0.992 \\
\hline Sumber: Data primer, 2020 (diolah) &
\end{tabular}

Berdasarkan Tabel 5, dapat dilihat hasil dari R-square dari model penelitian. Untuk konstruk Y (preferensi wakaf uang) memiliki nilai R-square sebesar 0.992. Hal tersebut menunjukkan bahwa variabel $\mathrm{Y}$ (preferensi wakaf uang) dipengaruhi oleh variabel $\mathrm{X}_{1}$ (religiusitas), $\mathrm{X}_{2}$ (literasi wakaf uang), $X_{3}$ (inklusi wakaf uang), dan $X_{4}$ (tata kelola lembaga wakaf uang) sebesar 0.992 atau 99.2\%, sisanya sebesar $8 \%$ dijelaskan oleh variabel lain di luar penelitian ini.

\section{Uji Hipotesis}

Uji hipotesis dalam inner model menggunakan nonparametric test untuk menentukan tingkat signifikan yang dihasilkan dengan algoritma bootstrapping pada SmartPLS. Hal ini dilakukan karena pada SmartPLS tidak mengasumsikan normalitas dan distribusi data. Maka, path coefficient dan nilai t-statistic (t-hitung dibandingkan dengan t-tabel) yang dihasilkan menguji apakah hipotesis diterima atau ditolak Jika t-statistik > t-tabel (t-tabel pada tingkat kepercayaan 95\% adalah 1.96), pada alpha $5 \%$ maka hipotesis diterima dan P-value $<0.05$ artinya signifikan memengaruhi. Berikut ini adalah hasil output bootsraping pada penelitian ini:

Tabel 6 Path coefficient

\begin{tabular}{|c|c|c|c|c|c|}
\hline & $\begin{array}{c}\text { Original } \\
\text { Sample } \\
\text { (O) }\end{array}$ & $\begin{array}{c}\text { Sample } \\
\text { Mean } \\
\text { (M) }\end{array}$ & $\begin{array}{l}\text { Standard } \\
\text { Deviation } \\
\text { (STDEV) }\end{array}$ & $\begin{array}{l}\text { T Statistics } \\
(|O / S T D E V|)\end{array}$ & $\begin{array}{c}P \\
\text { Values }\end{array}$ \\
\hline $\begin{array}{llll}\text { X1 (Religiusitas) } & \text {-> } & \text { Y } & \text { (Preferensi } \\
\text { Wakaf Uang) } & & & \\
\end{array}$ & 0.002 & 0.001 & 0.010 & 0.177 & 0.860 \\
\hline $\begin{array}{l}\text { X2 (Literasi Wakaf) -> Y (Preferensi } \\
\text { Wakaf Uang) }\end{array}$ & 0.186 & 0.187 & 0.015 & 12.335 & 0.000 \\
\hline $\begin{array}{l}\text { X3 (Inklusi Wakaf) -> Y (Preferensi } \\
\text { Wakaf Uang) }\end{array}$ & 0.477 & 0.476 & 0.020 & 0 & 0.000 \\
\hline $\begin{array}{l}\text { X4 (Tata Kelola Lembaga Wakaf } \\
\text { Uang) -> Y (Preferensi Wakaf Uang) }\end{array}$ & 0.464 & 0.463 & 0.021 & 21.825 & 0.000 \\
\hline
\end{tabular}

Sumber: Data primer, 2020 (diolah)

Tabel 6 merupakan hasil uji model struktural yang dilakukan untuk melihat nilai $t$-statistic yang akan digunakan sebagai penentu diterima atau ditolaknya sebuah hipotesis. Dengan signifikansi sebesar 5\% $=\mathrm{t}$-tabel 1.96, jika t-statistik > t-tabel maka hipotesis diterima (Hair et al., 2013). Berdasarkan tabel uji hipotesis dapat diambil kesimpulan bahwa variabel $\mathrm{X}_{1}$ (religiusitas) tidak berpengaruh signifikan terhadap Y (preferensi wakaf uang) karena memiliki nilai $t$-statistic sebesar $0.177(0.177<1.96$. Hal itu menunjukkan hipotesis pertama tidak diterima.

Hasil pengujian hipotesis pertama menunjukkan bahwa pengaruh variabel religiusitas terhadap preferensi wakaf uang adalah positif tapi tidak signifikan. Hasil ini bertolak belakang dengan berbagai penelitian yang menemukan bahwa religiusitas merupakan faktor dominan yang memengaruhi seseorang untuk berpartisipasi dalam wakaf uang (Shukor et al., 2017; Mokthar, 2016; Johari et al., 2015; Faradis, 2015). Namun, hasil studi ini sejalan dengan temuan Alhidari (2013) yang menyatakan 
bahwa religiusitas tidak berpengaruh sama sekali terhadap perilaku donasi di Saudi Arabia. Alasannya adalah karena melakukan donasi (infak, sedekah dan wakaf) merupakan nilai universal bagi masyarakat yang telah tertanam dalam diri setiap individu.

Menurut Alhidari (2013), individual yang memegang teguh nilai dasar seperti kebaikan dan universalisme dapat memotivasi mereka untuk melakukan donasi karena bisa meningkatkan taraf hidup orang yang membutuhkan. Salah satu jenis motivasi indivdiu dalam beramal adalah altruistik (Konrath \& Handy, 2018). Individu altruistik yaitu beramal karena mereka ingin memaksimalkan kesenangan dan kesejahteraan penerima (Batson, 1991 dalam Jamal et al., 2019) dan tidak mengharapkan imbalan apapun (Bierhoff, 1987 dalam Jamal et al., 2019).

Berdasarkan The World Giving Index tahun 2018, Indonesia menjadi top list negara yang suka memberi dan kedua tertinggi sebagai pemberi uang untuk beramal. Artinya, sifat saling menolong terutama berdonasi merupakan sifat alamiah dan telah menjadi jati diri dari setiap warga negara Indonesia meskipun berasal dari agama, suku dan ras yang berbeda. Apalagi di Sumatera Barat dengan masyarakat Minangkabau memiliki filosofi adat basandi syarak, syarak basandi kitabullah (adat berdasarkan hukum Islam, hukum Islam berdasarkan Al-Qur'an), di mana kebiassan tolong menolong merupakan kebiasaan masyarakat yang berpedoman pada Al-Qur'an.

Alasan lain adalah karena seseorang menyukai berdonasi jika mengetahui siapa penerima donasinya (Saroglou dan Galand 2004). Bahkan mereka lebih cenderung berdonasi ketika targetnya adalah teman dan keluarga terdekat (Reitsma et al., 2006). Konsep ini sebenarnya sejalan dengan agama Islam namun telah mengakar kuat sebagai nilai yang umum diterapkan oleh masyarakat bahwa orang yang pertama dibantu adalah keluarga dan tetangga.

Selanjutnya, uji hipotesis kedua dapat disimpulkan bahwa hipotesis $\mathrm{X}_{2}$ (literasi wakaf uang) terbukti berpengaruh signifikan terhadap Y (preferensi wakaf uang) karena memiliki besaran nilai $t$-statistic sebesar 12.335 (12.335 > 1.96). Hal itu menunjukkan hipotesis diterima. Hipotesis kedua dapat diterima berarti ada hubungan positif dan signifikan antara variabel literasi wakaf dengan preferensi wakaf uang.

Hasil penelitian ini sejalan dengan Adeyemi et al. (2016), Mokthar (2016), Yusof et al. (2013), Siswantoro dan Dewi (2011). Indeks literasi wakaf di Indonesia tergolong di bawah masuk dalam kategori rendah dengan skor sebesar 50.48 (BWI, 2020), dan indeks literasi wakaf uang cenderung rendah atau masuk kategori kurang baik (BKF Kemenkeu, 2019). Individu yang memiliki literasi wakaf yang lebih baik akan cenderung berpartisipasi dalam wakaf uang (Osman et al., 2012). Pengetahuan tentang wakaf uang berupa perbedaan wakaf uang dengan filantropi lain, istilah wakaf uang, informasi lembaga resmi pengelolaan wakaf, dan program penyaluran wakaf uang merupakan beberapa faktor yang sangat menentukan pemahaman wakaf uang sehingga dapat meningkatkan partisipasi wakaf uang.

Pada hipotesis ketiga, $\mathrm{X}_{3}$ (inklusi wakaf uang) terbukti berpengaruh signifikan terhadap $\mathrm{Y}$ (preferensi wakaf uang) karena memiliki nilai $t$-statistic sebesar $23.790(23.790>1.96)$. Hal itu menunjukkan hipotesis diterima. Hipotesis ketiga dapat diterima berarti variabel inklusi wakaf uang berpegaruh positif dan signifikan terhadap preferensi publik terhadap wakaf uang. Hasil penelitian yang sama ditemukan oleh Johari et al. (2015), BKF Kemenkeu (2019), dan Shukor et al. (2017). Individu akan mudah berpartisipasi dalam wakaf uang jika mereka telah percaya pada nazir, merasa nyaman dan mudah mengakses lembaga wakaf, serta penggunaan teknologi digital dalam wakaf uang.

Terakhir, pada hipotesis keempat $\mathrm{X}_{4}$ (tata kelola lembaga wakaf uang) terbukti berpengaruh signifikan terhadap Y (preferensi wakaf uang) karena memiliki nilai $t$-statistic sebesar 21.825 (21.825 > 1.96). Hal itu menunjukkan hipotesis diterima. Hipotesis keempat dapat diterima berarti bahwa variabel tata kelola lembaga wakaf uang berpengaruh positif dan signifikan pada preferensi wakaf uang di Sumatera Barat. Hal ini sejalan dengan hasil penelitian sebelumnya yang dilakukan oleh Adeyemi et 
al. (2016), Faradis (2015), Hasim et al. (2016), dan Johari et al. (2015). Masyarakat akan cenderung berpartisipasi dalam wakaf uang jika tata kelola lembaga wakaf dianggap kredibel. Mereka akan melihat profesionalitas lembaga, efesiensi manajemen lembaga wakaf, program dan inovasi program lembaga wakaf uang yang dapat diketahui melalui media, peruntukan dana wakaf uang, dan laporan penggunaan wakaf uang yang dengan mudah dapat diakses.

Berdasarkan uji model struktural, terdapat tiga variabel yang berpengaruh signifikan terhadap preferensi wakaf uang di Sumatera Barat yaitu literasi, inklusi dan tata kelola wakaf uang. Literasi wakaf uang di Sumatera Barat masuk kategori rendah dengan skor 54.95. Salah satu cara meningkatkan literasi wakaf uang adalah dengan melibatkan seluruh stakeholder terkait untuk sosialisasi dan edukasi masyarakat secara proaktif. Strategi yang dapat dilakukan terkait inklusi dan tata kelola wakaf uang adalah dengan menyediakan akses informasi, fasilitas dan transparansi laporan pengelolaan wakaf uang oleh lembaga wakaf uang. Selain itu, kemampuan nazir baik dalam hal pengetahuan wakaf uang baik hard skill maupun soft skill sangat penting dalam mendukung manajemen pengelolaan wakaf uang secara efisien. Lembaga wakaf uang harus adaptif terhadap perkembangan teknologi dalam hal promosi, edukasi maupun dalam sistem pengumpulan dan penyaluran wakaf uang.

\section{SIMPULAN}

Berdasarkan hasil analisis dalam penelitian ini, literasi, inklusi dan tata kelola wakaf merupakan faktor positif dan signifikan yang memengaruhi preferensi publik terhadap wakaf uang di Sumatera Barat. Berarti ketiga faktor ini harus menjadi fokus perhatian untuk bahan pertimbangan oleh pemerintah dan lembaga wakaf dalam rangka mendorong partisipasi masyarakat dalam wakaf uang. Literasi dapat ditingkatkan dengan kerjasama yang baik antarlembaga yang berwenang seperti pemerintah, lembaga wakaf, praktisi, maupun akademisi dalam rangka melakukan sosialisasi pada masyarakat luas untuk meningkatkan kesadaran dan pemahaman masyarakat tentang wakaf uang. Misalnya, dengan kajian-kajian wakaf uang yang disampaikan di masjid ataupun di media online seperti Youtube.

Sedangkan faktor inklusi dan tata kelola berkaitan dengan lembaga wakaf itu sendiri. Lembaga wakaf perlu melakukan pembenahan diri agar citra di masyarakat baik sehingga menimbulkan kepercayaan yang pada akhirnya memengaruhi seseorang untuk berwakaf uang. Salah satunya bisa memanfaatkan media digital untuk melalukan promosi dan penyampaian program-program wakaf uang sehingga informasi wakaf uang mudah didapatkan oleh masyarakat. Saran untuk pengembangan penelitian selanjutnya adalah mencoba menganalisis faktor yang memengaruhi seseorang untuk terus berwakaf uang. Hal menarik lain yang perlu dikembangkan dalam penelitian selanjutnya adalah permasalahan yang dihadapi lembaga pengelola wakaf uang.

\section{DAFTAR PUSTAKA}

Abdillah, W. \& Hartono, J. (2015). Partial Least Square (PLS)-Alternatif Structural Equation Modeling (SEM) dalam Penelitian Bisnis. Yogyakarta (ID), Andi.

Adeyemi, A. A., Ismail, N. A. \& Hassan, S. S. B. (2016). An empirical investigation of the determinants of cash waqf awareness in Malaysia. Intellectual Discourse, 24, 501-520.

Affandi, A. \& Nufus, D. N. (2010). Analysis on cash waqf return fund allocation in Indonesia: A case study in Indonesian waqf deposit. In Seventh International Conference-The Tawhidi Epistemology: Zakat and Waqf Economy (pp. 119-135).

Al-Ghazali. (1995). Ihya' Ulüm al-Dìn. Beirut (LB), Dar al-Fikr.

Alhidari, I. S. (2014). Investigating Individuals' Monetary Donation Behaviour in Saudi Arabia. (Doctoral Dissertation, Cardiff University, Cardiff, United Kingdom).

Alsanie, S. (1989). Relationship Between the Level of Religiosity and Criminal Behaviour. Jeddah (SA), Imam Ibn Suad Islamic University Press. 
Az-Zuhaili, Wahbah. (2011). Fiqih Islam Wa Adillatuhu. (Abdul Hayyie al-Kattani, dkk, Terjemahan). Jakarta (ID), Gema Insani.

Benjamin, D. J., Choi, J. J. \& Fisher, G. (2016). Religious identity and economic behavior. Review of Economics and Statistics, 98(4), 617-637. https://doi.org/10.1162/REST_a_00586.

Bennett, R. \& Savani, S. (2003). Predicting the accuracy of public perceptions of charity performance. Journal of Targeting, Measurement and Analysis for Marketing, 11(4), 326- 342.

[BKF Kemenkeu] Badan Keuangan Fiskal Kementerian Keuangan (2019). Strategi Pengembangan Wakaf Uang dalam Rangka Pendalaman Pasar Keuangan Syariah [Internet]. [diunduh 2020 Mar 20]. Tersedia pada: https://fiskal.kemenkeu.go.id/data/document/2019/kajian/Kajian_Stra tegi_Pengembangan_Wakaf_Uang.pdf.

[BWI] Badan Wakaf Indonesia. (2020). Laporan Hasil Survey Indek Literasi Wakaf 2020 [Internet]. [diakses 2020 April 30]. Tersedia pada: https://www.bwi.go.id/wp-content/uploads/2020/05/ 20200519-Indeks-Literasi-Wakaf-Indonesia-Tahun-2020-Edit.pdf.

Cohen, J. (1992). Statistical power analysis. Current Directions in Psychological Science, 1(3), 98101. https://doi.org/10.1111/1467-8721.ep10768783.

Dahlan, R. (2017). Impresi nazhir terhadap pemahaman wakaf uang. Al-Urban: Jurnal Ekonomi Syariah dan Filantropi Islam, 1(2), 176-188.

[DD] Dompet Dhuafa. (2019). Wakaf Pertama dalam Sejarah Islam [Internet]. [diakses 2020 Mar 10]. Tersedia pada: http://dompetdhuafa.org/id/berita/detail/wakaf-pertama-dalam-sejarahislam.

de Abreu, M. E., Laureano, R. M., da Silva, R. V. \& Dionísio, P. (2015). Volunteerism, compassion and religiosity as drivers of donations practices. International Journal of Nonprofit and Voluntary Sector Marketing, 20(3), 256-276.

[DEKS BI dan DES FEB UNAIR] Departemen Ekonomi dan Keuangan Syariah Bank Indonesia dan Departemen Ekonomi Syariah Fakultas Ekonomi dan Bisnis Universitas Airlangga. (2016). Wakaf: Pengaturan dan Tata Kelola yang Efektif. Jakarta (ID), Departemen Ekonomi dan Keuangan Syariah Bank Indonesia.

Faradis, J. (2015). The determinants of waqf preference toward money-cash waqf. Global Review of Islamic Economics and Business, 2(3), 219-229.

Hair, J. F., Hult, J. G. T. M., Ringle, C. M. \& Sarstedt, M. (2014). A primer on partial least squares structural equation modeling. Long Range Planning, 46(1-2). https://doi.org/10.1016/j.lrp.2013 .01 .002 .

Hasim, K., Lubis, D. \& Ali, K. M. (2016). Analisis faktor-faktor yang memengaruhi penghimpunan wakaf uang di Indonesia (pendekatan analytical network process). Al-Muzara'ah, 4(2), 127141.

Huda, N., Anggraini, D., Rini, N., Hudori, K. \& Mardoni, Y. (2014). Akuntabilitas sebagai sebuah solusi pengelolaan wakaf. Jurnal Akuntansi Multiparadigma, 5(3), 485-497. https://doi.org/10.1 8202/jamal.2014.12.5036.

Jamal, A., Yaccob, A., Bartikowski, B. \& Slater, S. (2019). Motivations to donate: Exploring the role of religiousness in charitable donations. Journal of Business Research, 103, 319-327. https://doi.org/10.1016/j.jbusres.2019.01.064.

Johari, F., Alias, M. H., Shukor, S. A., Wahab, K. A., Aziz, M. R. A., Ahmad, N., Zulkefli, Z. K. Hussin, F. A. \& Ibrahim, P. (2015). Factors that influence repeat contribution of cash waqf in Islamic philanthropy. Management and Accounting Review, 14(2), 55-78.

Juanda, B. (2009). Ekonometrika Pemodelan dan Pendugaan. Bogor (ID), IPB Press.

Kasri, R. A. (2013). Giving behaviors in Indonesia: Motives and marketing implications for Islamic charities. Journal of Islamic Marketing, 4(3), 306-324. https://doi.org/10.1108/JIMA-05-20110044.

[Kemenag RI] Kementerian Agama Republik Indonesia. (2020). Data Tanah Wakaf [Internet]. [diakses 2020 Mar 17]. Tersedia pada: http://siwak.kemenag.go.id.

[Kemenag Sumbar] Kementerian Agama Sumatera Barat. (2019). Data - data Kementerian Agama Tahun 2015 - 2019 [Internet]. [diakses 2020 Mar 15]. Tersedia pada: https://sumbar.kemenag. go.id/v2/post/50551/data\#.

[KNEKS] Komite Nasional Ekonomi dan Keuangan Syariah. (2019). Menangkap Peluang Tren 
Wakaf Produktif [Internet]. [diakses 2020 Apr 10]. Tersedia pada https://knks.go.id/storage/ upload/1569306459-KNKS\%20Edisi\%20Keempat\%20-\%20September.pdf.

Konrath, S. \& Handy, F. (2018). The development and validation of the motives to donate scale. Nonprofit and Voluntary Sector Quarterly, 47(2), 347-375. https://doi.org/10.1177/0899764017 744894.

Lambarraa, F. \& Riener, G. (2015). On the norms of charitable giving in Islam: Two field experiments in Morocco. Journal of Economic Behavior and Organization, 118, 69-84. https://doi.org/10.1016/j.jebo.2015.05.006.

McDaniel, S. W. \& Burnett, J. J. (1990). Consumer religiosity and retail store evaluative criteria. Journal of the Academy of Marketing Science, 18(2), 101-112. https://doi.org/10.1007/BF02726 426.

Mokthar, M. Z. (2016). Perceptions of Universiti Sains Malaysia Muslim staff on factors influencing their intention to perform cash waqf. Journal of Islamic Studies and Culture, 4(2), 101-109. https://doi.org/10.15640/jisc.v4n2a11.

[MUI] Majelis Ulama Indonesia. (2002). Wakaf Uang [Internet]. [diakses 2020 Mei 20]. Tersedia pada: http://mui.or.id/wp-content/uploads/files/fatwa/29.-Wakaf-Uang.pdf.

Nizar, A. (2014). Faktor-faktor yang memengaruhi persepsi wakif tentang wakaf uang. Esensi: Jurnal Bisnis Dan Manajemen, 4(1), 21-36. https://doi.org/10.15408/ess.v4i1.1953.

Setiadi, N. J. (2013). Perilaku Konsumen (edisi revisi). Jakarta (ID), Kencana Perdana Media Grup.

[OJK] Otoritas Jasa Keuangan. (2016). Survei Nasional Literasi dan Inklusi Keuangan 2016. [Internet]. [diakses 2020 Mei 30]. Tersedia pada: https://www.ojk.go.id/id/berita-dankegiatan/siaran-pers/Documents/Pages/Siaran-Pers-OJK-Indeks-Literasi-dan-Inklusi-KeuanganMeningkat/17.01.23\%20Tayangan\%20\%20Presscon\%20\%20nett.compressed.pdf.

Opoku, R. A. (2013). Examining the motivational factors behind charitable giving among young people in a prominent Islamic country. International Journal of Nonprofit and Voluntary Sector Marketing, 18(3), 172-186. https://doi.org/10.1002/nvsm.1457.

Osman, A. F., Htay, S. N. N. \& Muhammad, M. O. (2012, April). Determinants of cash waqf giving in Malaysia: Survey of selected works. In Workshop Antarbangsa Pembangunan Berteraskan Islam V (WAPI-5) (Vol. 10).

Osman, A. F., Mohammed, M. O. \& Amin, H. (2014, April). An analysis of cash waqf participation among young intellectual. In 9th International Academic Conference, Istanbul.

Puad, N. A. M., Rafdi, N. \& Shahar, W. S. S. B. (2014, May). Issues and challenges of waqf instrument: A case study in MAIS. In E-Proceedings of the Conference on Management and Muamalah, pp. 116-127.

Reitsma, J., Scheepers, P. \& Grotenhuis, M. Te. (2006). Dimensions of individual religiosity and charity: Cross-national effect differences in European countries? Review of Religious Research, 47(4), 347-362.

Siswantoro, D. \& Dewi, M. K. (2007, March). The effectiveness of waqf fund raising through mutual fund in Indonesia. In Singapore International Waqf Conference (Vol. 7).

Shukor, S. A., Anwar, I. F., Aziz, S. A. \& Sabri, H. (2017). Muslim attitude towards participation in cash waqf: Antecedents and consequences. International Journal of Business and Society, 18, 193-204.

Saroglou, V. \& Galand, P. (2004). Identities, values, and religion: A study among Muslim, other immigrant, and native Belgian young adults after the 9/11 attacks. Identity: An International Journal of Theory and Research, 4(2), 97-132.

Syafiq, A. (2014). Wakaf tunai untuk pemberdayaan usaha kecil. Jurnal Zakat Dan Wakaf, 1(2), 125.

Yusof, M. A., Aziz, M. R. A., \& Johari, F. (2013, September). The relationship between level of income and willingness of Muslim community to contribute for Islamic Waqf bank. In 5th Islamic Economic System Conference (pp. 36-89). 